\title{
Spatio-temporal patterns in acoustic presence and distribution of Antarctic blue whales Balaenoptera musculus intermedia in the Weddell Sea
}

\author{
Karolin Thomisch $^{1, *}$, Olaf Boebel ${ }^{1}$, Christopher W. Clark ${ }^{2}$, Wilhelm Hagen ${ }^{3}$, \\ Stefanie Spiesecke ${ }^{1}$, Daniel P. Zitterbart ${ }^{1,4,5}$, Ilse Van Opzeeland ${ }^{1}$ \\ ${ }^{1}$ Ocean Acoustics Lab, Alfred-Wegener-Institut, Helmholtz-Zentrum für Polar- und Meeresforschung, 27570 Bremerhaven, \\ Germany \\ ${ }^{2}$ Bioacoustics Research Program, Cornell University, 159 Sapsucker Woods Road, Ithaca, NY 14850, USA \\ ${ }^{3}$ BreMarE - Bremen Marine Ecology, Marine Zoology, University of Bremen, PO Box 330440, Bremen, Germany \\ ${ }^{4}$ Applied Ocean Physics and Engineering Department, Woods Hole Oceanographic Institution, Woods Hole, MA 02543, USA \\ ${ }^{5}$ Biophysics Lab, Department of Physics, University of Erlangen-Nuremberg, PO Box 3520, 91054 Erlangen, Germany
}

\begin{abstract}
Distribution and movement patterns of Antarctic blue whales Balaenoptera musculus intermedia at large temporal and spatial scales are still poorly understood. The objective of this study was to explore spatio-temporal distribution patterns of Antarctic blue whales in the Atlantic sector of the Southern Ocean, using passive acoustic monitoring data. Multi-year data were collected between 2008 and 2013 by 11 recorders deployed in the Weddell Sea and along the Greenwich meridian. Antarctic blue whale Z-calls were detected via spectrogram cross-correlation. A Blue Whale Index was developed to quantify the proportion of time during which acoustic energy from Antarctic blue whales dominated over background noise. Our results show that Antarctic blue whales were acoustically present year-round, with most call detections between January and April. During austral summer, the number of detected calls peaked synchronously throughout the study area in most years, and hence, no directed meridional movement pattern was detectable. During austral winter, vocalizations were recorded at latitudes as high as $69^{\circ} \mathrm{S}$, with sea ice cover exceeding $90 \%$, suggesting that some Antarctic blue whales overwinter in Antarctic waters. Polynyas likely serve as an important habitat for baleen whales during austral winter, providing food and reliable access to open water for breathing. Overall, our results support increasing evidence of a complex and non-obligatory migratory behavior of Antarctic blue whales, potentially involving temporally and spatially dynamic migration routes and destinations, as well as variable timing of migration to and from the feeding grounds.
\end{abstract}

KEY WORDS: Passive acoustic monitoring • Antarctic blue whale $\cdot$ Balaenoptera musculus intermedia $\cdot$ Baleen whale migration $\cdot$ Southern Ocean

\section{INTRODUCTION}

For most baleen whales, seasonal long-distance migrations between cold, productive, high-latitude feeding areas and warmer, low-latitude breeding grounds are considered a fundamental life cycle fea-

*Corresponding author: karolin.thomisch@awi.de ture (Kellogg 1929, Mackintosh 1942, 1966). The factors driving baleen whale migration are still under debate and have been suggested to involve a higher survival rate for calves due to calmer waters and a decreased risk of predation by killer whales at low latitudes (Corkeron \& Connor 1999, Ford \& Reeves 
2008), as well as energetic advantages which increase the future reproductive success of calves born in warm waters (Clapham 2001). Nevertheless, evidence is accumulating that the concept of a complete annual migration in baleen whales is unlikely to hold true for many baleen whale species (e.g. Ingebrigsten 1929, Kellogg 1929, Brown et al. 1995, Dawbin 1997, Širović et al. 2004, Branch et al. 2007). Instead of migrating to lower latitudes after the feeding season, part of the population remains in polar and subpolar waters during winter, indicating partial migration (see also Dingle \& Drake 2007) in many species (e.g. Bockstoce et al. 2005, Moore et al. 2006, Stafford et al. 2007, Acevedo et al. 2011, Van Opzeeland et al. 2013b).

For blue whales Balaenoptera musculus in the Southern Ocean, historical catch data suggest that migration is not obligatory and that timing of migration may vary between individuals (e.g. Mackintosh \& Wheeler 1929, Harmer 1931, Hjort et al. 1932). Blue whales were caught off South Georgia yearround (Harmer 1931, Hjort et al. 1932, Branch et al. 2007), suggesting this species exhibits partial or differential migration (i.e. part of the population either does not migrate or delays migration based on age, sex or reproductive stage). Furthermore, the composition of the blue whale population on the Southern Ocean whaling grounds changed considerably over austral summer, further supporting the hypothesis of a differential migratory behavior (Mackintosh \& Wheeler 1929). While adult whales were predominant in the population during austral spring, immature whales and lactating females did not arrive on the feeding grounds until February (Mackintosh \& Wheeler 1929, Harmer 1931, Hjort et al. 1932). Blue whale migratory behavior is therefore likely to be complex and staggered, resulting in a continuous, procession-like movement to and from feeding grounds (Mackintosh \& Wheeler 1929, Harmer 1931). Although both Antarctic blue whales (ABWs) Balaenoptera musculus intermedia and pygmy blue whales $B$. m. brevicauda inhabit the Southern Hemisphere, the latter were rarely sighted south of $55^{\circ} \mathrm{S}$ (Kato et al. 1995); therefore, most inferences on blue whale sightings from high-latitude waters are likely to represent ABWs.

After commercial whaling was banned, extensive visual sighting surveys were conducted in the Southern Ocean to monitor population abundance and behavior of ABWs, amongst other species (e.g. Kasamatsu et al. 1988, Branch \& Butterworth 2001, Branch et al. 2007). However, the species' low encounter rate, elusive character and low abundance, as well as the area's seasonal inaccessibility largely impede year-round data collection on ABW occurrence. But to explore patterns in the spatial distribution and-potentially staggered-migration of ABWs, year-round data are nevertheless a prerequisite.

Passive acoustic monitoring allows investigation of the large-scale spatio-temporal distribution of vocalizing individuals and, when applied in an array or network, provides information on movement patterns of vocalizing whales (e.g. Širović et al. 2004, Samaran et al. 2013, Risch et al. 2014). Furthermore, passive acoustic monitoring has the potential to yield seasonally unbiased information on marine mammal acoustic presence, hence being particularly valuable in remote areas which are not accessible year-round for visual surveys (e.g. Širović et al. 2004, Mellinger et al. 2007, Rettig et al. 2013, Van Opzeeland et al. 2013b). ABWs are particularly eligible for passive acoustic studies due to the repetitive production of different types of distinctive low-frequency vocalization (e.g. Ljungblad et al. 1998, Rankin et al. 2005) and the large propagation distances of these vocalizations (e.g. Širović et al. 2007, Miller et al. 2015). Consequently, passive acoustic monitoring has been increasingly used to study ABWs in the Southern Ocean, e.g. off the western Antarctic Peninsula, off eastern Antarctica and in the Ross Sea (Širović et al. 2004, 2009, Gedamke \& Robinson 2010, Miller et al. 2015). Similar to findings from blue whale populations inhabiting the North Atlantic and North Pacific Oceans (e.g. Clark \& Gagnon 2002, Charif \& Clark 2009, Stafford et al. 2009), the acoustic presence of ABWs exhibits a clear seasonal pattern in the Southern Ocean (Širović et al. 2004, 2009, Gedamke et al. 2007), often with a peak in call numbers during the respective summer season. Nevertheless, off the western Antarctic Peninsula, ABWs are acoustically present year-round, implying either a time-lagged migration or that some individuals omit migration to lower latitudes (Širović et al. 2004). However, to our knowledge, previous passive acoustic studies in the Southern Ocean have not been based on large-scale multi-year recorder networks in the open ocean, and hence little is known about distribution and movement patterns of ABWs in pelagic zones.

Here, we use multi-year data, recorded between 2008 and 2013 in the Weddell Sea and along the Greenwich meridian in the Atlantic sector of the Southern Ocean, to study the year-round distribution of vocalizing ABWs. One objective of our study was to investigate spatio-temporal patterns in the acoustic presence and distribution of ABWs within the 
study area, both intra- and inter-annually. Furthermore, we examined whether large-scale movement patterns can be detected from passive acoustic data in order to gain insight into the migratory behavior of ABWs. In this context, we explored the relation between the number of detected calls and the sea ice concentration within the study area to identify potential determinants and drivers of ABW distribution and migration patterns.

\section{MATERIALS AND METHODS}

\section{Acoustic data}

Between March 2008 and November 2013, passive acoustic recordings were collected by 14 moored devices, which were deployed in the Weddell Sea and along the Greenwich meridian for differing periods (Fig. 1, Table 1). The study area ranged from 59 to $69^{\circ} \mathrm{S}$ and from 0 to $27^{\circ} \mathrm{W}$ (Fig. 1). The study period comprised 3 consecutive periods of recorder deployment: March 2008December 2010; December 2010-December 2012; and December 2012-December 2014 (hereafter referred to as deployment periods I, II and III, respectively; see also Table 1). Most of the recording sites were monitored for at least 2 deployment pe-

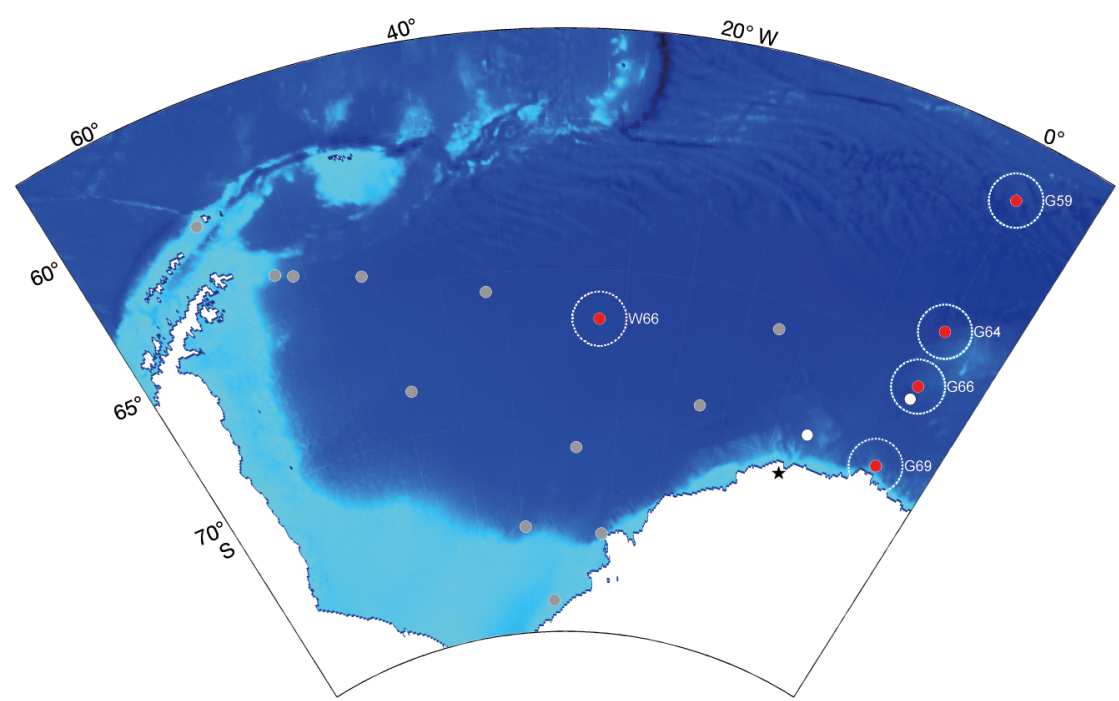

Fig. 1. Locations of autonomous recording devices, deployed between March 2008 and January 2013, in the Weddell Sea and Atlantic sector of the Southern Ocean. Positions of the acoustic recorders analyzed in this study (red dots), positions of recorders excluded from the analyses due to electronic noise (white dots) and locations of recorders not yet recovered (grey dots) are shown. Recorder IDs are shown in white (see also 'Materials and methods'; Table 1 ); $(\star)$ indicates the location of the Perennial Acoustic Observatory in the Antarctic Ocean (PALAO). Dashed circles indicate the area (radius of $100 \mathrm{~km}$ from the respective recording sites) used to calculate sea ice concentration riods (for nomenclature of recording sites and deployment periods see Table 1).

The acoustic recorders were either a self-contained lander or attached to oceanographic deep-sea moorings of the Hybrid Antarctic Float Observation System (HAFOS) (Rettig et al. 2013). A total of 3 types of acoustic recording device were utilized: SonoVaults (Develogic GmbH) (Rettig et al. 2013); Autonomous Underwater Recorder for Acoustic Listening (AURAL; Model 2, Multi-Électronique) (e.g. Simard et al. 2008); and a Marine Acoustic Recording Unit (MARU; contributed by the Bioacoustic Research Program, Cornell University, NY) (e.g. Parks et al. 2009). The acoustic recorders were moored at different depths and set to different duty cycles due to recorderspecific depth ratings and constraints of battery life and data storage capacities (see Table 1 for details of recorder specifications) (Rettig et al. 2013). Passive acoustic data were stored in 5 and $4.5 \mathrm{~min}$ files for the AURAL recorders, in $6 \mathrm{~min}$ files for the MARU device and in $10 \mathrm{~min}$ files for the SonoVault systems.

After retrieval, data quality of the recordings was inspected using long-term spectrograms of the recordings (calculating power spectral densities using Welch, fast Fourier transform [FFT] 16 384, Hamming window, $50 \%$ overlap). The AURAL recorders operated flawlessly for the entire period of their deployment. The SonoVault recorders stopped recording prior to their recovery due to battery exhaustion. Electronic noise was observed in both MARU and SonoVaults. In 2 SonoVaults (SV1002 and SV1005), persistent broadband noise masked parts of the acoustic signal. For this reason, these 2 recorders were excluded from further analyses. In the MARU, tonal noise occurred, which did not affect our analyses. Nonetheless, data recorded by MARU were excluded from all amplitude-related analyses due to the occasional occurrence of broadband noise. Further, 1 SonoVault (SV0001) failed to record underwater sound altogether, presumably due to a defective hydrophone or hydrophone connection.

In summary, the operational period of acoustic devices with utilizable recordings ranged from 6 to 34 mo (Table 1). Prior to further 


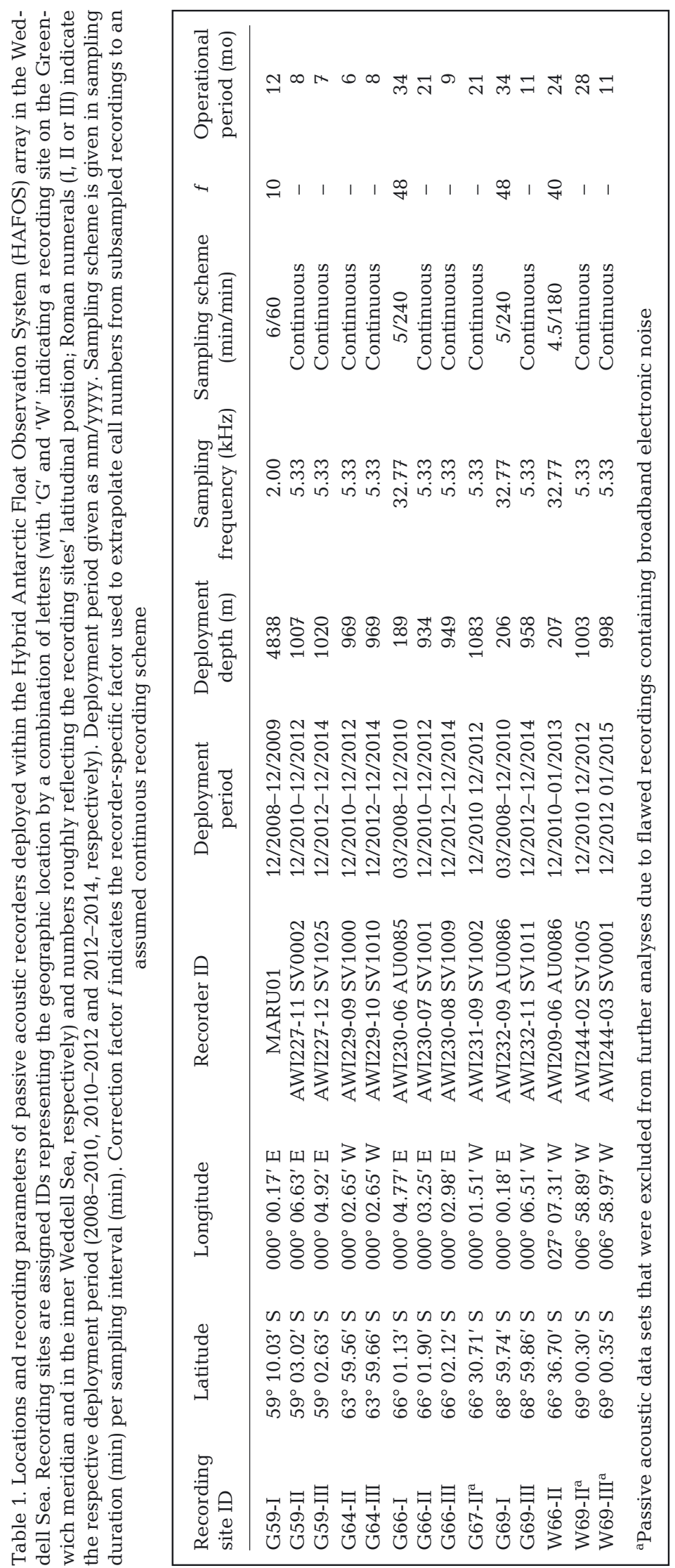

analyses, for all recorder types, passive acoustic data were downsampled (including an antialiasing FIR [finite impulse response] lowpass filter) to a uniform sampling rate of $250 \mathrm{~Hz}$ to obtain standardized data covering the frequency range of interest, i.e. below $125 \mathrm{~Hz}$.

\section{Sea ice data}

Sea ice cover in the study area was calculated using satellite data collected from 2008 to 2013 with a resolution of $6.25 \times 6.25 \mathrm{~km}$ (Spreen et al. 2008). Daily ice concentrations were calculated for an area of $3.1 \times 10^{4} \mathrm{~km}^{2}$ (representing a radius of $100 \mathrm{~km}$ ) around each recording site, including all data points located at a distance $\leq 100 \mathrm{~km}$ from the recording location. Given the large propagation ranges of ABW vocalizations and, hence, the potentially widespread spatial distribution of the recorded individuals around a respective recording location, we consider a radius of $100 \mathrm{~km}$ to be representative of sea ice conditions that ABWs are exposed to during their transit through or stay in the study area.

\section{Acoustic data analysis}

\section{ABW vocalizations}

One well-known ABW vocalization is the stereotyped, high-energy Z-call (named after its Z-shaped spectrographic signature) (Fig. 2) that is often produced in repetitive song patterns at regular intervals of about $62 \pm 5 \mathrm{~s}$ (Ljungblad et al. 1998, Širović et al. 2004, McDonald et al. 2006). A Z-call is composed of 3 units, starting with a constant frequency tone within the range of 26 to $28 \mathrm{~Hz}$ lasting about $9 \mathrm{~s}$ (Unit A), which is followed by a short downsweep (ca. $1 \mathrm{~s}$ ) to about $19 \mathrm{~Hz}$ (Unit B) and a slightly frequency-modulated tone of 18 to $19 \mathrm{~Hz}$ lasting 8 to $12 \mathrm{~s}$ (Unit C) (Ljungblad et al. 1998, Širović et al. 2004, Rankin et al. 2005). Long-term declines in vocalization frequency are evident in blue whale populations worldwide (McDonald et al. 2009, Gavrilov et al. 2012), and were also evident in the current data set. However, in-depth analyses of the decline pattern were beyond the scope of the present study. 


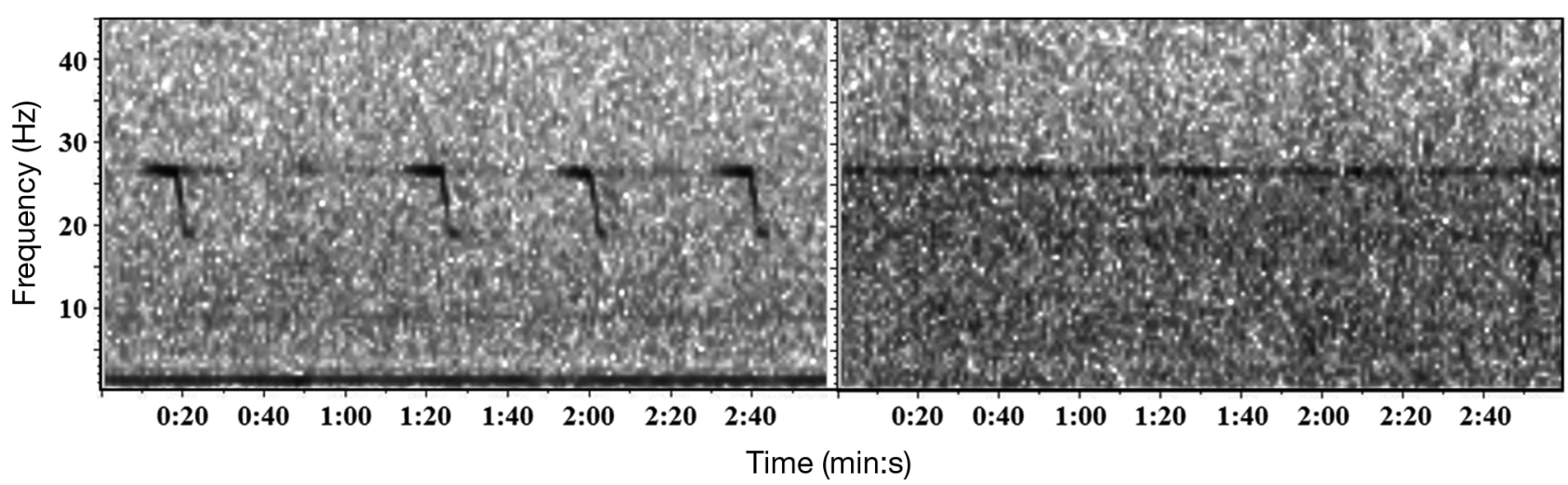

Fig. 2. Spectrogram of Antarctic blue whale song sequence of Z-calls (left panel) and chorus (right panel) recorded on 12 December 2010 at $59^{\circ} 03^{\prime} \mathrm{S}, 0^{\circ} 07^{\prime} \mathrm{E}$ and 10 March 2011 at $66^{\circ} 37^{\prime} \mathrm{S}, 2^{\circ} 08^{\prime} \mathrm{W}$, respectively (sample rate $250 \mathrm{~Hz}$ [after downsampling]; spectrogram settings: FFT 512 points, Hanning window, $50 \%$ overlap)

\section{Automated detection of single ABW Z-calls}

ABW Z-calls were detected by cross-correlating spectrograms with a pre-defined spectrogram template (e.g. Mellinger \& Clark 2000). Spectrograms were calculated for each audio file (FFT 1024, 500 point Hamming window, $75 \%$ overlap; resulting in frequency resolution of ca. $0.25 \mathrm{~Hz}$ and time resolution of ca. $0.5 \mathrm{~s}$ ). The template was created by averaging 100 temporally aligned spectrogram snippets of high-quality Z-calls (i.e. with all 3 call units being present) from 6 recorders and distributed over an overall period of 39 mo from December 2008 to February 2012 to ensure representativeness. This set of snippets also includes 12 Z-calls from recorder SV1002 (which was excluded from further analyses), which were recorded during a brief period without broadband noise. The final template had a frequency range of 18.5 to $28 \mathrm{~Hz}$ and was of $12 \mathrm{~s}$ duration (i.e. shorter than a 3-unit Z-call), containing $8 \mathrm{~s}$ of Unit A, Unit $B(=1 \mathrm{~s})$ and $3 \mathrm{~s}$ of Unit $\mathrm{C}$. These settings avoided biasing the detection results towards complete 3-unit Z-calls, because recorded ABW calls did not always comprise all 3 units, but most comprised (part of) Unit A or Units A + B (see also Rankin et al. 2005, Miller et al. 2015). Spectrogram cross-correlation was performed in time/frequency space for each audio file and in a frequency band from 17.5 to $29 \mathrm{~Hz}$. Interand intra-annual variations in the ABW Z-call frequency, e.g. the long-term decline in vocalization frequency, can affect the performance of a detector operating in a fixed frequency range. Therefore, the bandwidth of the frequency range to be analyzed (= $11.5 \mathrm{~Hz})$ was intentionally set broader than the Z-call template's bandwidth $(=9.5 \mathrm{~Hz})$ to allow crosscorrelation in both time and frequency space, accounting for a potential frequency shift of $\mathrm{ABW}$
Z-calls over time. A minimum separation of $15 \mathrm{~s}$ between detected events was preset to prevent biasing the results by detecting multipath arrivals of the same call, as exploratory manual analyses showed occurring in the MARU recordings.

Selection of a suitable detection threshold, which defines whether calls are considered present or not, is likely subject to biological, physical and methodological factors. The whales' calling behavior, location- and recorder-specific ambient noise levels, and the detector's performance all affect the number of effectively detected calls. To nevertheless allow comparisons of detection rates between the acoustic data sets recorded by different devices, at least to a certain extent, recorder-specific detection thresholds were adjusted to achieve a constant false alert rate for all recorders. Thresholds were calculated by correlating the Z-call template with a 'noise band' (29.5 to $39 \mathrm{~Hz}$ ), which does not contain any ABW Z-call units. Any detection within the noise band would therefore represent a false alert. Previous exploratory manual analyses showed that a correlation coefficient of 0.3 was the threshold at which all manually perceivable (true positive) Z-calls were detected. To determine the recorder-specific thresholds, a set of false positive detections was generated for each recorder by running the detector over the noise band with a threshold of 0.3 . From these false alerts, 1000 events were selected randomly and ranked according to their associated correlation coefficients. The minimum correlation coefficient associated with the best correlated $1 \%$ of false detections was selected. This procedure was repeated 1000 times per recorder and the respective minimum correlation coefficients were averaged $(\mathrm{n}=1000)$ to obtain a recorderspecific threshold (Table 2). While this approach is not sufficient to provide resilient data for abundance 
estimates or determining ABW call rates, relative and recorder-specific threshold setting provided a means to reliably compare detections between recorders for exploring spatio-temporal patterns in acoustic presence throughout our study area.

ABW Z-call detection was performed based on these thresholds representing a $1 \%$ false alert level, and numbers of calls detected per week ( $7 \mathrm{~d}$ bins) were calculated and used to correlate numbers of detected calls with sea ice concentration over time at the different recording sites. Assuming a uniform ABW call distribution without a diel pattern in our study area (see also Thomisch et al. 2015), weekly detection numbers from subsampled recordings were extrapolated to an assumed continuous recording period for direct comparability among data sets, using a recorder-specific factor that corrects for the respective duty cycle (Table 1 ). In addition, daily mean numbers of Z-call detections per minute were calculated. Time series of these daily mean detection rates were filtered to reduce variability in detected call numbers between days in order to focus on large-scale patterns in Z-call detections (SavitzkyGolay filtering, window length $=31$, step size $=1$, regression based on polynomial order 2). In contrast to smoothing approaches using linear regressions, the Savitzky-Golay filter (based on polynomial regression) keeps the actual data distribution intact in terms of small-scale patterns, such as local minima and maxima.

Table 2. Thresholds for Z-call detection using spectrogram cross-correlation and total number of detected Antarctic blue whale (ABW) Z-calls in passive acoustic data sets from the Weddell Sea and Atlantic sector of the Southern Ocean. Detection was based on a false-alert rate (FAR) of $1 \%$ as determined from detector performance within a frequency band $(29.5-39 \mathrm{~Hz})$ not containing any Z-calls. Determined detection thresholds (representing minimally required correlation coefficients) are given as mean (used for detection process) \pm SD. For a detailed description of detection threshold determination, see 'Materials and methods'

\begin{tabular}{|lccc|}
\hline $\begin{array}{l}\text { Recording } \\
\text { site }\end{array}$ & Recorder ID & $\begin{array}{c}\text { Detection threshold } \\
\text { for FAR 1\% }\end{array}$ & $\begin{array}{c}\text { Total no. detected } \\
\text { ABW Z-calls } \\
\text { at FAR 1 \% }\end{array}$ \\
\hline W66 & AWI209-06 AU0086 & $0.4573 \pm 0.0084$ & 18180 \\
G59 & MARU01 & $0.4939 \pm 0.0075$ & 7553 \\
& AWI227-11 SV0002 & $0.4725 \pm 0.0078$ & 147964 \\
G64 & AWI227-12 SV1025 & $0.4729 \pm 0.0077$ & 112004 \\
& AWI229-09 SV1000 & $0.4704 \pm 0.0088$ & 159336 \\
G66 & AWI229-10 SV1010 & $0.4748 \pm 0.0088$ & 132847 \\
& AWI230-06 AU0085 & $0.4709 \pm 0.0101$ & 9398 \\
G69 & AWI230-07 SV1001 & $0.4680 \pm 0.0085$ & 611580 \\
& AWI230-08 SV1009 & $0.4679 \pm 0.0082$ & 206335 \\
& AWI232-09 AU0086 & $0.4693 \pm 0.0071$ & 9287 \\
& AWI232-11 SV1011 & $0.4647 \pm 0.0083$ & 211724 \\
\hline
\end{tabular}

\section{Quantification of ABW chorus: Blue Whale Index (BWI)}

Z-calls (or, more explicitly, Unit A of the Z-calls) produced by distant ABWs create a tonal 'chorus' within the 26 to $28 \mathrm{~Hz}$ frequency band (Gedamke et al. 2007). Hence, detections of only single Z-calls may underestimate the acoustic presence of ABWs (Fig. 2). A Blue Whale Index (BWI) was designed to quantify the proportion of time during which the ABW chorus was more energetic than background noise, taking into account acoustic energy from both nearby and distant ABWs. The BWI is based on comparing energy levels in 3 different frequency bands, representing acoustic power in the signal band $(S)$ and in 2 adjacent noise bands. The signal band, with $26 \leq$ frequency $\leq 28 \mathrm{~Hz}$, comprises the ABW Z-call Unit A. The 2 noise bands, $N_{1}$ with $23 \leq$ frequency $\leq$ $24 \mathrm{~Hz}$ and $N_{\mathrm{u}}$ with $29 \leq$ frequency $\leq 30 \mathrm{~Hz}$, contain no spectral energy from ABW Z-call Unit A's, yet possibly negligible amounts of energy from Z-call Unit B's.

Band energy of the signal band was calculated by averaging power spectral densities ( $\mathrm{PSD}_{\text {; temporal }}$ resolution $0.5 \mathrm{~s}$, frequency resolution $0.25 \mathrm{~Hz}$ ) between 26 and $28 \mathrm{~Hz}$. Combined noise band $\left(N_{\mathrm{c}}\right)$ energy was obtained by averaging PSD values between 23 and $24 \mathrm{~Hz}$, and 29 and $30 \mathrm{~Hz}$. This process results in time series of the signal band $\varepsilon(S)$ and the combined noise band $\varepsilon\left(N_{\mathrm{c}}\right)$ between 4.5 and $10 \mathrm{~min}$ length, corresponding to the respective file length. From these, moving averages of band energy of $\varepsilon(S)$ and $\varepsilon\left(N_{c}\right)$ were calculated using a $5.5 \mathrm{~s}$ long averaging window in $0.5 \mathrm{~s}$ steps $t_{i}$ (i.e. over $\mathrm{k}=$ 11 samples) to obtain mean energy levels of signal band $\bar{S}$ and combined noise band $\bar{N}_{\mathrm{c}}$ respectively:

$$
\begin{gathered}
\bar{S}=\frac{1}{k} \sum_{t_{i}=1}^{k} \varepsilon_{S}\left(t_{i}\right) \\
\text { and } \\
\bar{N}_{\mathrm{c}}=\frac{1}{k} \sum_{t_{i}=1}^{k} \varepsilon_{N_{\mathrm{c}}}\left(t_{i}\right)
\end{gathered}
$$

Standard deviation of the combined noise band $\varepsilon\left(N_{\mathrm{c}}\right)$ was calculated accordingly.

For each data point (i.e. every $0.5 \mathrm{~s}$ ), we tested whether the mean signal band energy level was larger than the sum of the mean plus twice the stan- 
dard deviation of the energy level in the combined noise band, i.e. if

$$
\begin{aligned}
& 10 \times \log _{10}(\bar{S})>10 \times \log _{10}\left(\bar{N}_{c}\right)+ \\
& 2 \times\left\{10 \times \log _{10}\left[\operatorname{SD}\left(N_{\mathrm{c}}\right)\right]\right\}
\end{aligned}
$$

The BWI was defined as the ratio of occurrences when this criterion was met versus the total number of data points per file. For each file, this provides the percentage of time dominated by ABW acoustic energy in the signal band. Given that the BWI test criterion continuously adjusts to local ambient noise levels, it prevents interpreting (broadband) noise as ABW chorus. Accordingly, acoustic signatures such as fin whale pulses that contribute energy to both the signal and noise band will not meet the BWI criterion and, hence, do not bias the BWI.

Similar to the single Z-call data, time series of daily mean BWIs were calculated and smoothed using Savitzky-Golay filtering (window length $=31$, step size $=1$, regression based on polynomial order 2) .

\section{Recorder independence and distance estimations}

For reliable interpretation of single Z-call detections at different recording sites, it is essential to know whether recording sites are independent in terms of the recorded signals. For 2 recorder pairs, we tested whether the same ABW Z-call sequences were detectable at 2 recording sites quasi-simultaneously (see the Supplement at www.int-res.com/articles/suppl/ n030p239_supp.pdf). Furthermore, rough estimates of distances of ABWs from recording sites were calculated for each Z-call detection, assuming a source level of 189 dB (Širović et al. 2007) and using different reported transmission loss models (Širović et al. 2007, Breitzke \& Bohlen 2010, Van Opzeeland et al. 2013b) (see the Supplement for detailed information on amplitude measurements and distance estimation).

\section{RESULTS}

\section{Recorder independence}

The estimated distances of vocalizing ABWs from the recorders ranged from less than $2 \mathrm{~km}$ to more than $700 \mathrm{~km}$. However, for all recording sites, the majority of calls were estimated to have come from whales within a $200 \mathrm{~km}$ range of the recorder (see Fig. S1 in the Supplement at www.int-res.com/ articles/suppl/n030p239_supp.pdf). Consistent with this finding, Z-call sequences were rarely detected on more than one recorder at a time (Table S4 in the Supplement). Although a little overlap in the recorded signals may occur between adjacent recorders, this is unlikely to bias the results substantially. For further data interpretation, we therefore considered data sets from different recorders to be acoustically independent of each other.

\section{Acoustic presence}

ABWs were acoustically present at all recording sites in all years covered by this study. The total number of detected ABW Z-calls varied highly among recorders, depending on the sampling scheme as well as on the respective overall operational period of recorders, and ranged from 7553 detections at Site G59 (MARU) to 611580 at G66 (SV1001) at a detection threshold level accepting $1 \%$ false alerts (Table 2). Of all recording days at a respective site, $99 \%$ showed acoustic presence of ABWs at W66, $81 \%$ at G59, $100 \%$ at G64, 94\% at G66 and $83 \%$ at G69, based on detections of single Z-calls.

Manual perusal of the data revealed that song bouts with Z-calls repeated at regular intervals were present occasionally in our passive acoustic recordings. For the larger part, vocal activity was variable and temporally unstructured (i.e. occurring in irregular bouts).

\section{Spatio-temporal patterns in ABW Z-call detections and acoustic energy}

Single Z-calls

The number of detected calls was lower in the AURAL and MARU recordings than in SonoVault data during austral winter, presumably for a combination of reasons, including sampling scheme (see also Thomisch et al. 2015), occurrence of broadband noise and deployment depth.

A clear seasonal pattern in the number of detected ABW Z-calls was evident at all locations and in all years (Fig. 3). At most sites, detected call numbers showed a steep increase starting between December and January (except for G66-II and W66, where detection numbers started to increase in October), a peak between January and March (austral summer), and a decrease from April to September. ABWs remained acoustically present year-round with small 


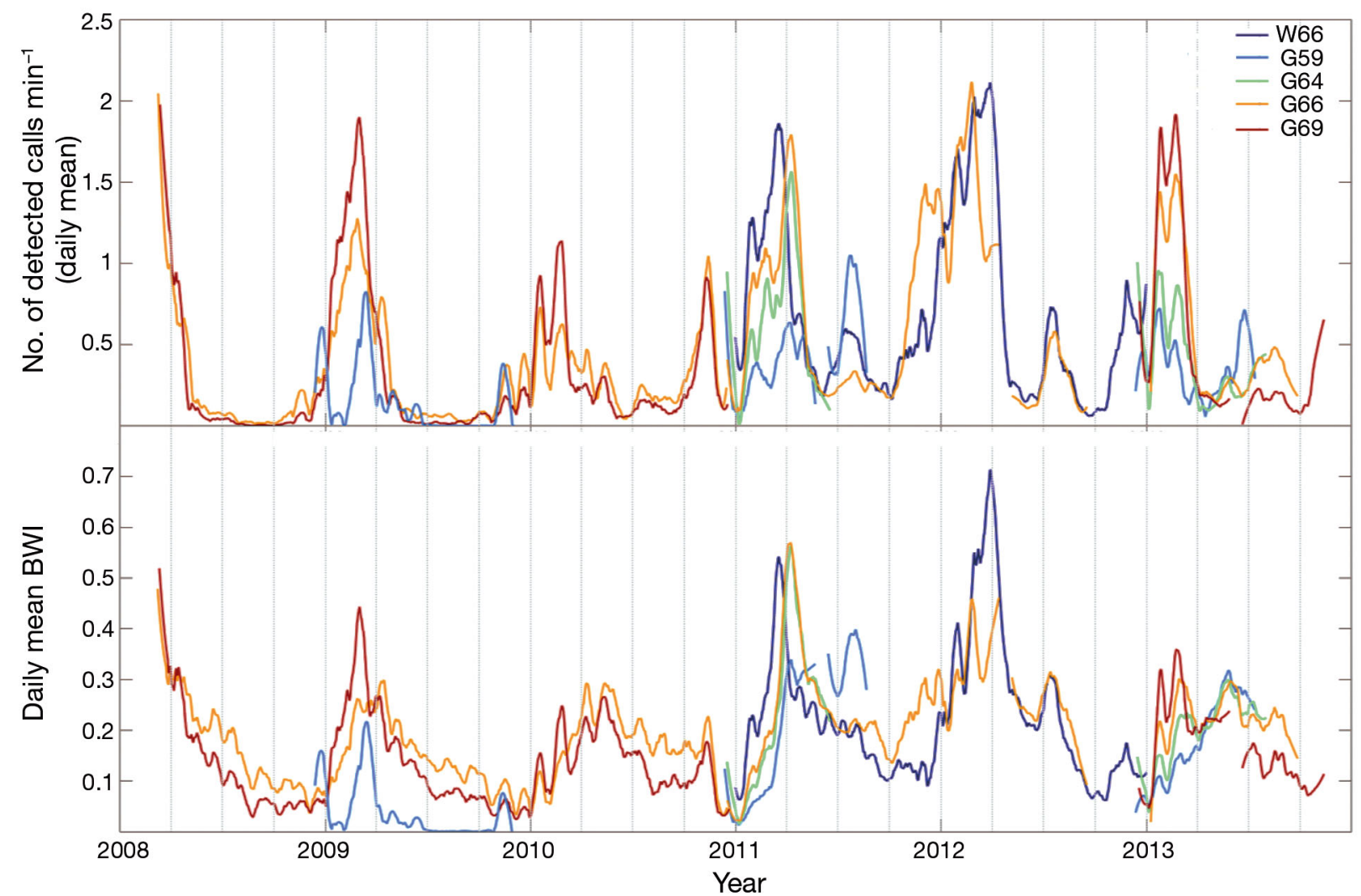

Fig. 3. Time series of Antarctic blue whale call detections and blue whale index (BWI) at different recording locations in the Weddell Sea and along the Greenwich meridian. Upper panel: daily mean number of detected Z-calls per minute, based on detections at a threshold level of $1 \%$ false alerts. Lower panel: BWI based on spectral energy in 26 to $28 \mathrm{~Hz}$ frequency band. Time series were smoothed using Savitzky-Golay filter (window length $=31$, polynomial order $=2$ ); colors represent different recording locations; vertical grey lines indicate beginnings of quarters of the year

numbers of Z-calls also detected during austral winter at all locations. At G59-II and -III, G66 and W66, the number of detected calls showed a secondary peak during winter (see also Table 1 for information on IDs). Only at G59-I were very few ABW vocalizations detected from July to October. Visual screening of winter recordings (July to October) from G59-I, however, revealed the presence of some faint Unit A's of Z-calls in July and August, which were discarded during automatic detection as these failed to meet the threshold requirements. ABW vocalizations were not detected visually in September and October at G59-I either.

At W66, G66 and G69, the timing of the peak in call detections during austral summer was relatively stable over time, while it varied between years at G59 (with most calls detected between November and April) and at G64 (most calls detected between December and April) (Fig. 4). Interestingly, in austral summer 2010/2011, most calls were detected in early April at G59, G64 and
G66, which was markedly delayed compared to all other recording years.

No, or only small, temporal shifts in the timing of the peak in call detections were discernable between recording locations in a meridional direction, i.e. north-south along the Greenwich meridian (Fig. 4). Only during austral summer 2008/2009 was a succession in the timing of the peaks in call detections evident, with numbers of detections peaking first at G59 at the end of December, followed by peaks at G66 at the end of February and at G69 at the beginning of March (Figs. 3 \& 4). In mid-March 2009, a secondary peak in detections was evident at G59. During all other years, the number of Z-call detections peaked synchronously at all recording sites along the Greenwich meridian. In a zonal direction, peaks in ABW call numbers showed temporal differences between W66 and G66. In the 2010/2011 season, the number of detected ABW calls was highest in mid-March at W66, which was about 3 wk earlier compared to the peak at G66. By contrast, in the following year, the 


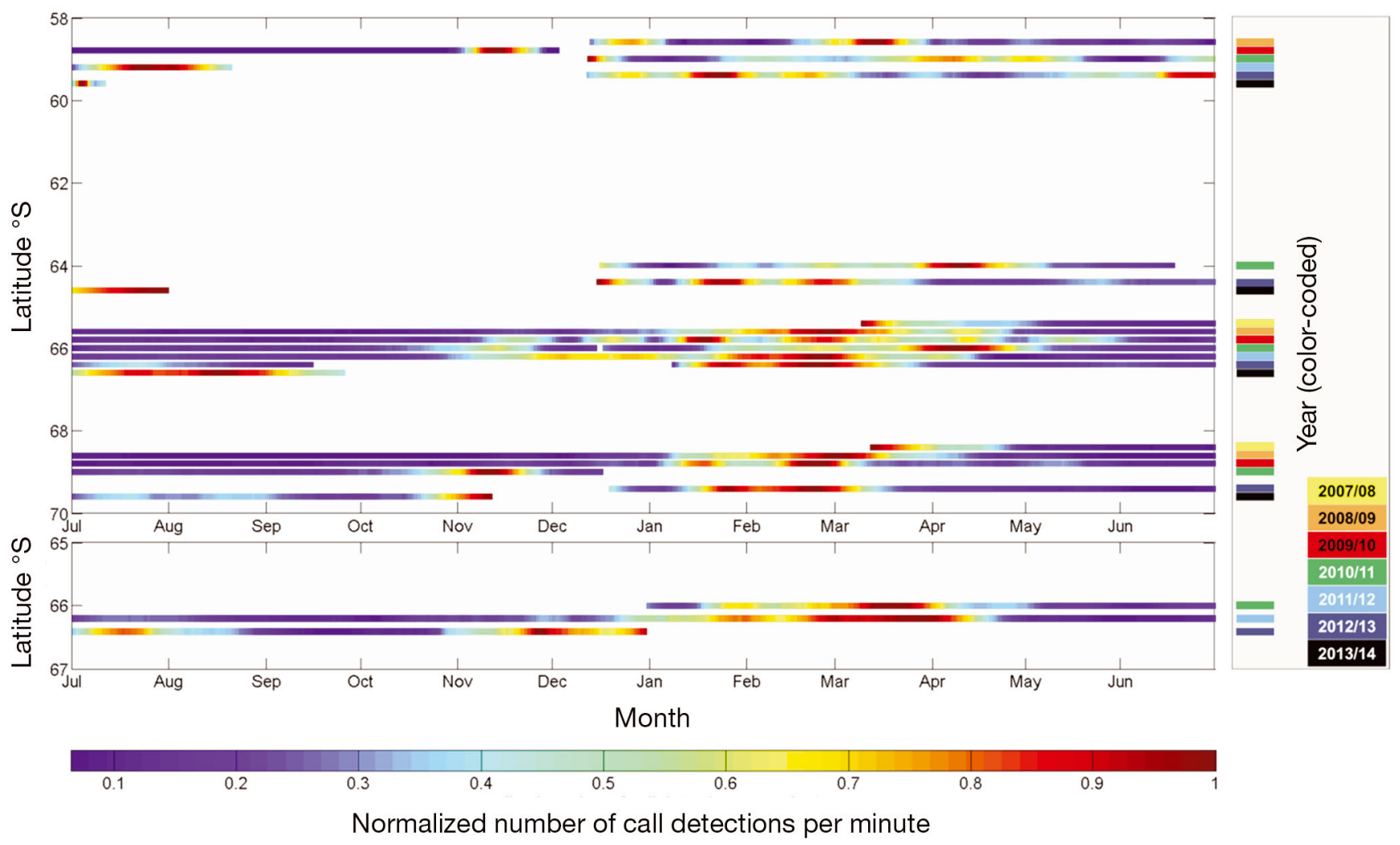

Fig. 4. Timing of peaks in numbers of Antarctic blue whale (ABW) call detections at different recording sites located along the Greenwich meridian (upper panel) and in the inner Weddell Sea (lower panel) over time. Recording sites were located at 59 ${ }^{\circ}$, $64^{\circ}, 66^{\circ}, 66^{\circ} 30^{\prime}, 68^{\circ}$ and $69^{\circ} \mathrm{S}$, respectively (see Fig. 1, Table 1), but are depicted slightly shifted depending on recording season for clearer presentation. Different bands represent different years/seasons (with a season defined as starting in July and ending in June of the next year) and are color-coded on the right. Colors of the bands themselves indicate the (normalized) level of ABW Z-call detections (numbers of detected calls per minute)

number of detections peaked first at G66 in late February 2012 (occurring about 5 wk earlier in 2012 than in 2011) and about 1 mo later (i.e. late March) at W66. Secondary peaks during austral winter were discernable at both recording sites during July.

\section{BWI}

For all sites and in all years, the mean BWI exhibited values above zero throughout the year, indicating that acoustic energy attributed to ABWs was always present in the recordings from the study area (Fig. 3). Similar to data from Z-calls, BWI data from G59-I formed an exception, with the mean BWI ranging close to zero from July through October. No clear differences in BWI between northern and southern recording sites were observed.

The BWI time series mirrored the seasonal variations in the number of Z-call detections at all recording sites, except for a slower decrease in autumn fol- lowing the BWI summer peak (Fig. 3). At most of the recording locations (W66, G59, G64-II, G66-II and G69-III), the BWI peak closely matched in time with the peak in Z-call detections. At G64-III, G66-I and G69-I, a delay of several weeks was observed between the timing of the BWI peak and the peak in single Z-call detections.

\section{Z-call detections in relation to sea ice concentration}

There was a distinct negative relation between the number of detected ABW Z-calls and ice coverage in the study area (Fig. 5). Over the study period, sea ice retreated between October and January, and started to form between March and July, depending on the recording site. Periods with open waters (defined as sea ice concentration $<15 \%$ ) were considerably longer at the northern recording sites (lasting up to 7 mo at G59) than at the southern recording sites (0 to 

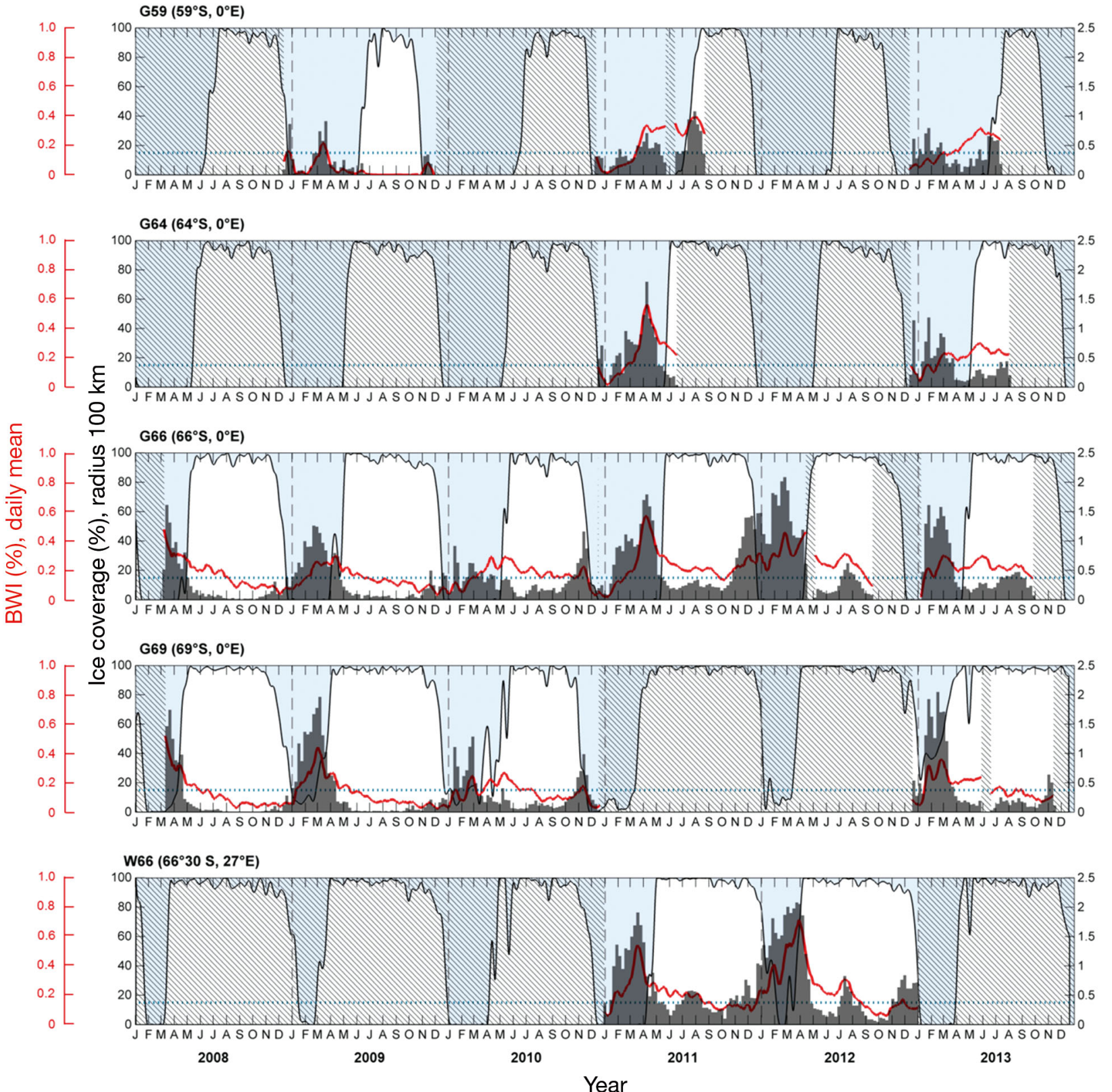

Fig. 5. Antarctic blue whale Z-call detections per week (dark grey bars, $7 \mathrm{~d}$ bins), BWI (red line, daily means) and sea ice concentration (black solid line, daily means within a $100 \mathrm{~km}$ radius) at different recording sites from 2008 to 2013 . White areas indicate sea ice coverage and blue areas indicate open water. Blue dotted line represents sea ice edge (15\% ice cover). Hatched areas indicate periods when no recordings are available. Vertical dashed grey lines indicate beginnings of years of the study period. Z-call detections from subsampled recordings were normalized to weekly values for direct comparability between data sets

2 mo at G69). In general, most vocalizations were detected during periods with no (W66, G59, G64, G66 and G69-I) or moderate (G69-III) sea ice concentrations, while considerably less calls were detected during periods with high (>90\%) sea ice coverage. At most locations (G59, G64, G66-I and G69), changes in the number of detections appeared to be closely related to changing ice conditions, i.e. sea ice retreat or formation. However, at W66, G66-II and
G66-III, Z-calls were also detected during periods of high $(>90 \%)$ sea ice concentration in winter. Furthermore, the number of detections already began to increase weeks to months before the sea ice retreated. At G69, the sea ice did not fully retreat during austral summer 2013; also at this location, many ABW Z-call detections were associated with moderate ice conditions (about $40 \%$ ice cover in January and February). 


\section{DISCUSSION}

\section{ABW distribution in the Weddell Sea}

The acoustic presence of ABWs along the Greenwich meridian in the Southern Ocean and in the inner Weddell Sea mirrors patterns in historic catch data, indicating a wide meridional distribution of ABWs in the Atlantic sector of the Southern Ocean (see review of Branch et al. 2007). At each of the recording sites, ABWs were acoustically present for more than $80 \%$ of all recording days each year, indicating that they are reliably present in Southern Ocean waters during much of the year, irrespective of ice conditions. Interestingly, in contrast to the present study and the historic catch data, postwhaling visual surveys showed that ABWs predominantly occurred close to the pack ice edge and continental shelf in austral summer (Branch et al. 2007). Although it cannot be excluded that the sighting effort was biased to some extent towards the summer months and the ice edge south of $60^{\circ} \mathrm{S}$, the overall reduced density of exploited ABW populations may also have caused whales to concentrate at the ice edge where krill is most abundant (Branch et al. 2007). Our data show ABW acoustic presence from 59 to $69^{\circ} \mathrm{S}$, implying a distribution of ABWs similar to that observed during the whaling era.

A recovery of the ABW population might have caused individuals to disperse and return to their former, much wider, distribution range (Branch et al. 2004, 2007). Nevertheless, possibilities to infer (local) abundances from our passive acoustic data are limited due to a detector artifact. Therefore, further inferences on whether potential changes in distribution could be reflective of increases in ABW abundance are impeded. The detector enables a total maximum of 4 vocalizations per minute to be detected, given a template duration of $12 \mathrm{~s}$ and a predefined minimum separation of $15 \mathrm{~s}$ between detected events (i.e. between the same part of 2 adjacent vocalizations). Assuming calls occur at regular intervals of about $1 \mathrm{~min}$, the maximum number of calling whales that it is technically possible to detect with our algorithm is 4 individuals. The BWI measurements do not suffer from these detector-specific limitations, as these determine ABW energy on a continuous time basis. However, inferences on the number of individuals from the BWI are not possible without essential knowledge of, for example, detection likelihood, the individual cue rate and how this relates to the BWI, information which is currently lacking for ABWs. Furthermore, it is likely that song sequences of $\mathrm{ABW}$
Z-calls represent a male reproductive display, analogous to behavioral patterns in other baleen whale species (e.g. Tyack 1981, Croll et al. 2002, Oleson et al. 2007). Abundance estimates based on Z-call activity would therefore only account for the reproductively active male part of the population.

\section{Acoustic presence in ice-covered areas}

The present study found ABWs to be acoustically present in ice-free waters as well as under moderate ice concentrations during austral summer, and in areas with $>90 \%$ ice cover during winter. Off the western Antarctic Peninsula, a negative correlation between ABW Z-calls and sea ice concentration suggested that ABWs are absent or scarce in ice-covered areas (Širović et al. 2004, Širović \& Hildebrand 2011, Dziak et al. 2015). Nevertheless, Double et al. (2015) also reported vocal aggregations of ABWs located in areas with non-navigable ice conditions in the Ross Sea during austral summer. Despite the fact that different metrics have been used by different studies to determine ice concentration and ice edge location, the results of Double et al. (2015), along with our findings, indicate that ABW distribution in open ocean environments, such as the Ross and Weddell Sea, is not principally restricted to ice-free waters, but that ABWs are capable of navigating (heavily) ice-covered areas as well.

Differences in krill distribution and hence food availability between the western Antarctic Peninsula and the Weddell and Ross Sea may explain the differential usage of ice-covered waters by ABWs. The waters west of the Antarctic Peninsula are highly productive in terms of phytoplankton and krill abundance during austral summer, governed by the proximity and seasonal convergence of the ice edge and the southern boundary of the Antarctic Circumpolar Current in this region (e.g. Tynan 1998, Atkinson et al. 2008). During winter, krill overwinter at greater depth on the shelf (Siegel 2005, Nicol 2006). ABWs in the western Antarctic Peninsula area may therefore primarily exploit high-density food patches coinciding with the ice edge during austral summer, while feeding in this area is possibly too inefficient during winter. Conversely, in the Weddell Sea, postlarval krill are less abundant and distributed over a wider geographic range than off the western Antarctic Peninsula (Tynan 1998). Nevertheless, an almost year-round, close association of krill with the underice-habitat persists in the Weddell/Lazarev Sea (Flores et al. 2012) and may therefore provide a reliable 
food source for ABWs and other baleen whales that is virtually continuously available in the ice-covered waters of our study area.

\section{Acoustic presence during austral winter}

Our data provide the southernmost record of ABW winter presence in the Southern Ocean. High ice concentrations during winter most likely inhibit large-scale movements of ABWs, particularly at the southernmost recording sites. Hence, ABW winter presence indicates that part of the population skips the energy-costly migration to lower latitudes and overwinters in cold, ice-covered waters of the Weddell Sea. By thus reducing energy expenditure, along with the opportunity for prolonged exploitation of food sources, this may primarily benefit female whales, especially young barren individuals without dependent calves (e.g. Brown et al. 1995). Furthermore, baleen whale mating is known not to be restricted spatially and temporally to low-latitude breeding grounds, but also occurs at high latitudes and outside the breeding season (Clark \& Clapham 2004). The presence of (presumably exclusively male) Z-calls therefore possibly indicates that a certain portion of ABW males also benefits from skipping migration by opportunistically mating with females that may have failed to conceive during summer and then overwinter in the Weddell Sea.

Besides the Weddell Sea, ABWs were also present year-round off South Georgia (Harmer 1931, Hjort et al. 1932), off the western Antarctic Peninsula (Širović et al. 2004, Dziak et al. 2015), in the southern Indian Ocean (Samaran et al. 2013) and in eastern Antarctica (Gedamke et al. 2007, Širović et al. 2009). Our study therefore adds to accumulating evidence that annual migration is not obligatory for ABWs and overwintering in the Southern Ocean may occur regularly and over large spatial scales. Local, potentially recurring, polynyas may enable ABWs and other marine mammals to overwinter in otherwise icecovered areas (Ainley et al. 2010), but are likely to spatially constrain animal movements to open water areas during winter (see also Van Opzeeland et al. 2013b). Decreasing trends in the sea ice extent and the length of the sea ice season (e.g. de la Mare 1997, Parkinson 2002, Cotté \& Guinet 2007) may potentially enable more extensive animal movements in the Weddell Sea during winter, but are likely to have severe effects on the Weddell Sea ecosystem due to an accompanying decline in krill densities (Atkinson et al. 2004).

\section{Inferring ABW migratory movements in the Weddell Sea from passive acoustic data}

ABWs are thought to emit Z-calls while travelling or migrating (Širović et al. 2009, Širović \& Hildebrand 2011), hence spatio-temporal differences in the timing of peak call numbers might reveal migratory movements of ABWs in our study area (see also Širović et al. 2004). However, we observed a virtually simultaneous gradual increase in vocal activity from November onwards. Moreover, the number of detected calls peaked synchronously along the Greenwich meridian, and hence, no evidence for a directed, meridional migration of vocalizing (presumably male) ABWs could be detected. Our data thus contrast with the observations of Double et al. (2015) that suggested a simultaneous onset of ABW acoustic activity after vocal inactivity at the beginning of the feeding season.

Our results possibly indicate that ABWs exhibit a complex migratory behavior, featuring partial and differential migration, as reported for many baleen whale species (e.g. Kellogg 1929, Mackintosh \& Wheeler 1929, Brown et al. 1995, Dawbin 1997, Craig et al. 2003, Širović et al. 2004). A (temporally or spatially) segregated and dynamic migration may result in a complex, staggered pattern of ABW movements to and from the feeding grounds, involving continuous arrivals and departures of individuals (see also Mackintosh \& Wheeler 1929, Harmer 1931, Širović et al. 2004, Samaran et al. 2013). Future studies employing satellite and passive acoustic tags or visual observations of acoustically tracked individuals (Miller et al. 2015) will be most valuable to further our understanding of the (vocal) behavior in different ABW sex or age classes and, in turn, enable more comprehensive inferences on the (acoustic) ecology of ABWs.

\section{CONCLUSIONS}

This study is the first to report year-round acoustic presence of ABWs in the Weddell Sea and along the Greenwich meridian based on multi-year passive acoustic data. Our results suggest that the Weddell Sea, and in particular coastal polynyas, serve as an important habitat for ABWs and other baleen whales throughout the year, most likely by supplying food resources and reliable access to open water for breathing (see also Van Opzeeland et al. 2013b).

The synchronous peak of call numbers and the virtually continuous presence of calls are potentially indicative of temporally and spatially dynamic mi- 
gration routes or destinations, as well as a temporally segregated migration depending on sex, age and reproductive status of the animals. Hence, our results add to the increasing evidence that a complex and dynamic migratory behavior, potentially including both partial and differential migration, is the rule rather than the exception for baleen whales. Further, evidence is accumulating that baleen whale feeding grounds are not static and confined locations, but rather dynamic areas providing a suitable habitat in terms of sea ice conditions, primary productivity and, in turn, krill abundance (Tynan 1998, Van Opzeeland et al. 2013b). Accordingly, blue whale feeding does not appear to be restricted in time and space, but has been observed to occur throughout the migration cycle year-round (Mate et al. 1999, Hucke-Gaete et al. 2004, Bailey et al. 2009, Silva et al. 2013). In turn, intra- and inter-annually variable environmental conditions that determine prey abundance and distribution, such as sea ice or ocean dynamics, may significantly influence the migratory behavior of baleen whales in terms of timing, routes and destinations (Mackintosh \& Wheeler 1929, Reilly \& Thayer 1990, Bailey et al. 2009).

A detailed understanding of distribution and migration patterns of baleen whales is of particular importance for assessing the effects of global change on high trophic levels. Recently, humpback and fin whales in the Gulf of Saint Lawrence were reported to migrate to their feeding grounds 2 wk earlier than 3 decades ago, possibly representing an earlier onset of primary production due to increased sea surface temperature and earlier sea ice breakup caused by global warming (Ramp et al. 2015). However, such notions need to be viewed critically in light of the overall variability of migratory patterns, or the direct and indirect long-term effects of commercial whaling on entire ecosystems. In this context, standardized data collection is essential to guarantee an accurate and integrative analysis of data, stemming from different areas, years and, in the case of passive acoustic data, different recording devices. Currently, the Southern Ocean Research Partnership (SORP) aims to set up the Southern Ocean Hydrophone Network (SOHN), a circumpolar hydrophone array intended to collect standardized, synchronously recorded passive acoustic data over multiple years with ABWs as a focal species (Van Opzeeland et al. 2013a). Once implemented, SOHN will provide detailed information on ABW occurrence and distribution on a circumAntarctic scale, indispensable for the design of effective conservation measures such as the designation of ecologically relevant marine protected areas.
Acknowledgements. Many thanks to Develogic $\mathrm{GmbH}$, Hamburg, Germany, to the logistics department of the Alfred Wegener Institute, Helmholtz Centre for Polar and Marine Research, Bremerhaven, Germany, and to Reederei F. Laeisz GmbH, Rostock, Germany, for their contribution to the development, setup or maintenance of the passive acoustic recording array. We thank Dominic Osztermayer for assistance with preliminary analyses of the passive acoustic data. We are grateful to Elke Burkhardt, Lars Kindermann, Marcel Nicolaus, Sandra Schwegmann and Stefanie Arndt for insightful comments and discussions on earlier versions of the manuscript. We also thank 3 anonymous reviewers for their constructive comments on an earlier draft that greatly improved the quality of our manuscript.

\section{LITERATURE CITED}

Acevedo J, Olavarría C, Plana J, Aguayo-Lobo A, Larrea A, Pastene L (2011) Occurrence of dwarf minke whales (Balaenoptera acutorostrata subsp.) around the Antarctic Peninsula. Polar Biol 34:313-318

Ainley DG, Tynan CT, Stirling I (2010) Sea ice: a critical habitat for polar marine mammals and birds. In: Thomas DN, Dieckmann GS (eds) Sea ice. Blackwell Publishing, Oxford, p 240-266

Atkinson A, Siegel V, Pakhomov E, Rothery P (2004) Longterm decline in krill stock and increase in salps within the Southern Ocean. Nature 432:100-103

Atkinson A, Siegel V, Pakhomov EA, Rothery P and others (2008) Oceanic circumpolar habitats of Antarctic krill. Mar Ecol Prog Ser 362:1-23

Bailey H, Mate BR, Palacios DM, Irvine L, Bograd SJ, Costa DP (2009) Behavioural estimation of blue whale movements in the Northeast Pacific from state-space model analysis of satellite tracks. Endang Species Res 10:93-106

Bockstoce JR, Botkin DB, Philp A, Collins BW, George JC (2005) The geographic distribution of bowhead whales, Balaena mysticetus, in the Bering, Chukchi, and Beaufort Seas: evidence from whaleship records, 1849-1914. Mar Fish Rev 67:1-43

Branch TA, Butterworth DS (2001) Estimates of abundance south of $60^{\circ} \mathrm{S}$ for cetacean species sighted frequently on the $1978 / 79$ to $1997 / 98$ IWC/IDCR-SOWER sighting surveys. J Cetacean Res Manag 3:251-270

Branch TA, Matsuoka K, Miyashita T (2004) Evidence for increases in Antarctic blue whales based on Bayesian modelling. Mar Mamm Sci 20:726-754

Branch TA, Stafford KM, Palacios DM, Allison C and others (2007) Past and present distribution, densities and movements of blue whales Balaenoptera musculus in the Southern Hemisphere and northern Indian Ocean. Mammal Rev 37:116-175

Breitzke M, Bohlen T (2010) Modelling sound propagation in the Southern Ocean to estimate the acoustic impact of seismic research surveys on marine mammals. Geophys J Int 181:818-846

Brown MR, Corkeron PJ, Hale PT, Schultz KW, Bryden MM (1995) Evidence for a sex-segregated migration in the humpback whale (Megaptera novaeangliae). Proc R Soc B 259:229-234

Charif RA, Clark CW (2009) Acoustic monitoring of large whales in deep waters north and west of the British Isles: 1996-2005. Cornell Laboratory of Ornithology Bioacoustics Research Program Tech Rep 08-07. Cornell Uni- 
versity Lab of Ornithology Bioacoustics Research Program, Ithaca, NY

Clapham P (2001) Why do baleen whales migrate? Mar Mamm Sci 17:432-436

Clark CW, Clapham P (2004) Acoustic monitoring on a humpback whale (Megaptera novaeangliae) feeding ground shows continual singing into late spring. Proc R Soc B 271:1051-1057

Clark CW, Gagnon GC (2002) Low-frequency vocal behaviors of baleen whales in the North Atlantic: insights from IUSS detections, locations and tracking from 1992 to 1996. J Underwater Acoust 52:609-640

- Corkeron PJ, Connor RC (1999) Why do baleen whales migrate? Mar Mamm Sci 15:1228-1245

$>$ Cotté C, Guinet C (2007) Historical whaling records reveal major regional retreat of Antarctic sea ice. Deep-Sea Res I 54:243-252

Craig AS, Herman LM, Gabriele CM, Pack AA (2003) Migratory timing of humpback whales (Megaptera novaeangliae) in the central North Pacific varies with age, sex and reproductive status. Behaviour 140: 981-1001

- Croll DA, Clark CW, Acevedo A, Tershy B, Flores S, Gedamke J, Urban J (2002) Only male fin whales sing loud songs. Nature 417:809

Dawbin W (1997) Temporal segregation of humpback whales during migration in Southern Hemisphere waters. Mem Queensl Mus 42:105-138

de la Mare WK (1997) Abrupt mid-twentieth-century decline in Antarctic sea-ice extent from whaling records. Nature 389:57-60

Dingle H, Drake VA (2007) What is migration? Bioscience 57:113-121

Double MC, Miller BS, Leaper R, Olson P and others (2015) Cruise report on blue whale research from the NZ/Aus Antarctic Ecosystems Voyage 2015 of the Southern Ocean Research Partnership. Paper SC/66a/SH7 presented to the IWC Scientific Commitee, May 2015, San Diego, CA

Dziak RP, Bohnenstiehl DR, Stafford KM, Matsumoto H and others (2015) Sources and levels of ambient ocean sound near the Antarctic Peninsula. PLoS ONE 10:e0123425

> Flores H, van Franeker JA, Siegel V, Haraldsson M and others (2012) The association of Antarctic krill Euphausia superba with the under-ice habitat. PLoS ONE 7:e31775

> Ford JKB, Reeves RR (2008) Fight or flight: antipredator strategies of baleen whales. Mammal Rev 38:50-86

$>$ Gavrilov AN, McCauley RD, Gedamke J (2012) Steady inter and intra-annual decrease in the vocalization frequency of Antarctic blue whales. J Acoust Soc Am 131: 4476-4480

Gedamke J, Robinson SM (2010) Acoustic survey for marine mammal occurrence and distribution off East Antarctica (30-80 ${ }^{\circ}$ ) in January-February 2006. Deep-Sea Res II 57: 968-981

Gedamke J, Gales N, Hildebrand J, Wiggins S (2007) Seasonal occurrence of low frequency whale vocalisations across eastern Antarctic and southern Australian waters, February 2004 to February 2007. Paper SC/59/SH57 presented to the IWC Scientific Committee, May 2007, Anchorage, AK

Harmer SF (1931) Southern whaling. Proc Linn Soc Lond 142:85-163

Hjort J, Lie J, Ruud JT (1932) Norwegian pelagic whaling in the Antarctic. Hvalrådet Skrifter 3:1-37
Hucke-Gaete R, Osman LP, Moreno CA, Findlay KP, Ljungblad DK (2004) Discovery of a blue whale feeding and nursing ground in southern Chile. Proc R Soc B 271: S170-S173

Ingebrigsten A (1929) Whales caught in the North Atlantic and other seas. ICES Rep 56:3-26

Kasamatsu F, Hembree D, Joyce G, Tsunoda L, Rowlett R, Nakano T (1988) Distribution of cetacean sightings in the Antarctic: results obtained from the IWC/IDCR minke whale assessment cruises, 1978/79 to 1983/84. Rep Int Whaling Comm 38:449-487

Kato H, Miyashita T, Shimada H (1995) Segregation of the two sub-species of the blue whale in the Southern Hemisphere. Rep Int Whaling Comm 45:273-283

Kellogg R (1929) What is known of the migrations of some of the whalebone whales. Smithsonian Inst Ann Rep 1928: 467-494

Ljungblad DK, Clark CW, Shimada H (1998) A comparison of sounds attributed to pygmy blue whales (Balaenoptera musculus brevicauda) recorded south of the Madagascar Plateau and those attributed to 'true' blue whales (Balaenoptera musculus) recorded off Antarctica. Rep Int Whaling Comm 48:439-442

Mackintosh NA (1942) The southern stocks of whalebone whales. Discov Rep 22:236-260

Mackintosh NA (1966) The distribution of southern blue and fin whales. In: Norris K (ed) Whales, dolphins and porpoise. University of California Press, Berkeley, CA

Mackintosh NA, Wheeler JFG (1929) Southern blue and fin whales. Discov Rep 1:257-540. https://archive.org/ stream/discoveryreports01257540inst/discoveryreports 01257540inst_djvu.txt

Mate BR, Lagerquist BA, Calambokidis J (1999) Movements of North Pacific blue whales during the feeding season off southern California and their southern fall migration. Mar Mamm Sci 15:1246-1257

McDonald MA, Mesnick SL, Hildebrand JA (2006) Biogeographic characterisation of blue whale song worldwide: using song to identify populations. J Cetacean Res Manag 8:55-65

McDonald MA, Hildebrand JA, Mesnick S (2009) Worldwide decline in tonal frequencies of blue whale songs. Endang Species Res 9:13-21

Mellinger DK, Clark CW (2000) Recognizing transient lowfrequency whale sounds by spectrogram correlation. J Acoust Soc Am 107:3518-3529

> Mellinger DK, Stafford KM, Moore S, Dziak RP, Matsumoto $H$ (2007) An overview of fixed passive acoustic observation methods for cetaceans. Oceanography (Wash DC) 20:36-45

Miller BS, Barlow J, Calderan S, Collins K and others (2015) Validating the reliability of passive acoustic localisation: a novel method for encountering rare and remote Antarctic blue whales. Endang Species Res 26:257-269

> Moore SE, Stafford KM, Mellinger DK, Hildebrand JA (2006) Listening for large whales in the offshore waters of Alaska. Bioscience 56:49-55

> Nicol S (2006) Krill, currents, and sea ice: Euphausia superba and its changing environment. Bioscience 56: 111-120

> Oleson EM, Wiggins SM, Hildebrand JA (2007) Temporal separation of blue whale call types on a southern California feeding ground. Anim Behav 74:881-894

Parkinson CL (2002) Trends in the length of the Southern Ocean sea-ice season, 1979-99. Ann Glaciol 34:435-440 
Parks SE, Urazghildiiev I, Clark CW (2009) Variability in ambient noise levels and call parameters of North Atlantic right whales in three habitat areas. J Acoust Soc Am 125:1230-1239

Ramp C, Delarue J, Palsbøll PJ, Sears R, Hammond PS (2015) Adapting to a warmer ocean - seasonal shift of baleen whale movements over three decades. PLoS ONE 10:e0121374

Rankin S, Ljungblad D, Clark C, Kato H (2005) Vocalisations of Antarctic blue whales, Balaenoptera musculus intermedia, recorded during the 2001/2002 and 2002/2003 IWC/SOWER circumpolar cruises, Area V, Antarctica. J Cetacean Res Manag 7:13-20

Reilly SB, Thayer VG (1990) Blue whale (Balaenoptera musculus) distribution in the eastern tropical Pacific. Mar Mamm Sci 6:265-277

Rettig S, Boebel O, Menze S, Kindermann L, Thomisch K, Van Opzeeland I (2013) Local to basin scale arrays for passive acoustic monitoring in the Atlantic sector of the Southern Ocean. In: Papadakis J, Bjorno L (eds) International Conference and Exhibition on Underwater Acoustics, 23-28 June 2013, Corfu Island, Greece. http://www. uaconferences.org/docs/proceedings/2013/UA2013Pro ceedings.pdf

Risch D, Castellote M, Clark C, Davis G and others (2014) Seasonal migrations of North Atlantic minke whales: novel insights from large-scale passive acoustic monitoring networks. Mov Ecol 2(2):1-17

Samaran F, Stafford KM, Branch TA, Gedamke J, Royer JY, Dziak RP, Guinet C (2013) Seasonal and geographic variation of southern blue whale subspecies in the Indian Ocean. PLoS ONE 8:e71561

Siegel V (2005) Distribution and population dynamics of Euphausia superba: summary of recent findings. Polar Biol 29:1-22

Silva MA, Prieto R, Jonsen I, Baumgartner MF, Santos RS (2013) North Atlantic blue and fin whales suspend their spring migration to forage in middle latitudes: Building up energy reserves for the journey? PLoS ONE 8:e76507

Simard Y, Roy N, Gervaise C (2008) Passive acoustic detection and localization of whales: effects of shipping noise in Saguenay - St. Lawrence Marine Park. J Acoust Soc

Editorial responsibility: Robert Harcourt, Sydney, New South Wales, Australia
Am 123:4109-4117

Širović A, Hildebrand JA (2011) Using passive acoustics to model blue whale habitat off the Western Antarctic Peninsula. Deep-Sea Res II 58:1719-1728

Širović A, Hildebrand JA, Wiggins SM, McDonald MA, Moore SE, Thiele D (2004) Seasonality of blue and fin whale calls and the influence of sea ice in the Western Antarctic Peninsula. Deep-Sea Res I 51:2327-2344

Širović A, Hildebrand JA, Wiggins SM (2007) Blue and fin whale call source levels and propagation range in the Southern Ocean. J Acoust Soc Am 122:1208-1215

Širović A, Hildebrand JA, Wiggins SM, Thiele D (2009) Blue and fin whale acoustic presence around Antarctica during 2003 and 2004. Mar Mamm Sci 25:125-136

Spreen G, Kaleschke L, Heygster G (2008) Sea ice remote sensing using AMSR-E 89-GHz channels. J Geophys Res Oceans 113:C2S03, doi:10.1029/2005JC003384

Stafford KM, Moore SE, Spillane M, Wiggins S (2007) Gray whale calls recorded near Barrow, Alaska, throughout the winter of 2003-04. Arctic 60:167-172

Stafford KM, Citta JJ, Moore SE, Daher MA, George JE (2009) Environmental correlates of blue and fin whale call detections in the North Pacific Ocean from 1997 to 2002. Mar Ecol Prog Ser 395:37-53

Thomisch K, Boebel O, Zitterbart DP, Samaran F, Van Parijs S, Van Opzeeland I (2015) Effects of subsampling of passive acoustic recordings on acoustic metrics. J Acoust Soc Am 138:267-278

Tyack P (1981) Interactions between singing Hawaiian humpback whales and conspecifics nearby. Behav Ecol Sociobiol 8:105-116

> Tynan CT (1998) Ecological importance of the Southern Boundary of the Antarctic Circumpolar Current. Nature 392:708-710

Van Opzeeland IC, Samaran F, Stafford KM, Findlay K, Gedamke J, Harris D, Miller BS (2013a) Towards collective circum-antarctic passive acoustic monitoring: the Southern Ocean hydrophone network (SOHN). Polarforschung 83:47-61

> Van Opzeeland I, Van Parijs S, Kindermann L, Burkhardt E, Boebel O (2013b) Calling in the cold: pervasive acoustic presence of humpback whales (Megaptera novaeangliae) in Antarctic coastal waters. PLoS ONE 8:e73007

Submitted: November 25, 2015; Accepted: May 2, 2016 Proofs received from author(s): June 27, 2016 